\title{
BACTERIAL PRODUCTION OF 7-FORMAMIDOCEPHALOSPORINS ISOLATION AND STRUCTURE DETERMINATION
}

\author{
Pushra D. Singh, Marian G. Young, Janice H. Johnson, \\ Christopher M. Cimarusti and Richard B. Sykes \\ The Squibb Institute for Medical Research \\ P. O. Box 4000 \\ Princeton, New Jersey 08540, U.S.A. \\ (Received for publication February 29, 1984)
}

\begin{abstract}
Two new 7-formamidocephalosporins have been isolated as their acetyl derivatives (SQ 28,516 and SQ 28,517) from fermentations of a Flavobacterium sp. SC 12,154. Structure 1 was deduced for SQ 28,516 from its spectroscopic properties while structure $\mathbf{2}$ was proposed for SQ 28,517. SQ 28,516 exhibits weak antibacterial activity.
\end{abstract}

The production of $\beta$-lactam antibiotics by bacteria has been recently reported; these include monobactams $^{1 \sim 9)}$, a carbapenem ${ }^{10)}$ and a cephalosporin ${ }^{11)}$. During a screening program developed to detect $\beta$-lactam antibiotics produced by bacteria ${ }^{3)}$, we isolated a strain of Flavobacterium sp. that produces deacetoxycephalosporin $\mathrm{C}^{11)}$ and a mixture of novel 7-substituted cephalosporins. A description of the producing strain and its fermentation conditions has been reported previously ${ }^{11)}$. This paper describes the isolation and structure determination of two cephalosporins, SQ 28,516 (1) and SQ 28,517 (2) (Fig. 1). The biological properties of SQ 28,516 are also presented.

\section{Isolation Procedure}

The fermentation of Flavobacterium sp. SC 12,154 produced a mixture of cephalosporins; deacetoxycephalosporin $\mathrm{C}$ was found in the cells ${ }^{11}$ ) whereas a mixture of 7 -substituted cephalosporins was present in the broth supernate. Antibiotic production in the fermentation broth and the isolation of the 7-substituted cephalosporins, as their acetyl derivatives, were monitored using Bacillus licheniformis (SC 9262) as the test organism. The isolation and purification procedure is outlined in Fig. 2.

The fermentation broth contained a mixture of antibiotics which were cationic at $\mathrm{pH} 2.3 \sim 7.0$ and anionic at $\mathrm{pH}$ 9.2. The antibiotics themselves were heat and $\mathrm{pH}$ labile, and all attempts to isolate them were unsuccessful. However, their acetyl derivatives were somewhat more stable and the antibiotics were therefore isolated as their acetyl derivatives. The fermentation broth was centrifuged, the supernate adjusted to $\mathrm{pH} 4.0$ and the bioactive components were absorbed on a strongly acidic ion-exchange resin and acylated with acetic anhydride. The acetyl derivatives, SQ 28,516 and SQ 28,517, were further purified by a combination of adsorption, ion-exchange and reverse-phase chromatography.

\section{SQ 28,516}

The major antibiotic of the fermentation, isolated as the $N, N^{\prime}$-diacetyl derivative, SQ 28,516 (1), is a water soluble, amphoteric cephalosporin (electrophoresis data in Table 1), $[\alpha]_{\mathrm{D}}^{25}-2.6^{\circ}\left(c 1.05, \mathrm{H}_{2} \mathrm{O}\right)$. The UV spectrum showed a $\lambda_{\max }$ at $263 \mathrm{~nm}\left(\mathrm{E}_{\mathrm{lcm}}^{1 \%} 69\right)$ and the IR spectrum in $\mathrm{KBr}$ exhibited bands at 1770 ( $\beta$-lactam carbonyl), 1720 (ester) and 1650 (secondary amide) $\mathrm{cm}^{-1}$. The spectral data, taken together with the origin of SQ 28,516 in a screen specific for $\beta$-lactam antibiotics, strongly suggested a 
Fig. 1. Structures of SQ 28,516, SQ 28,517 and the hydrolysis product (3).

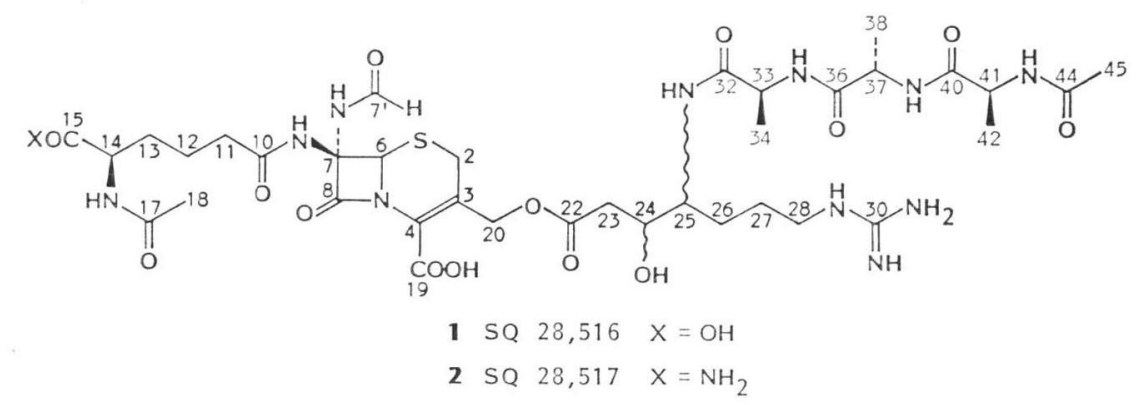<smiles>CC(=O)N[C@@H](C)C(=O)N[C@@H](I)C(=O)N[C@@H](C)C(=O)NCCC(CCCCNC(=N)N)C(O)CC(=O)O</smiles>

(Hydrolysis product)

Fig. 2. Isolation of SQ 28,516 and SQ 28,517.

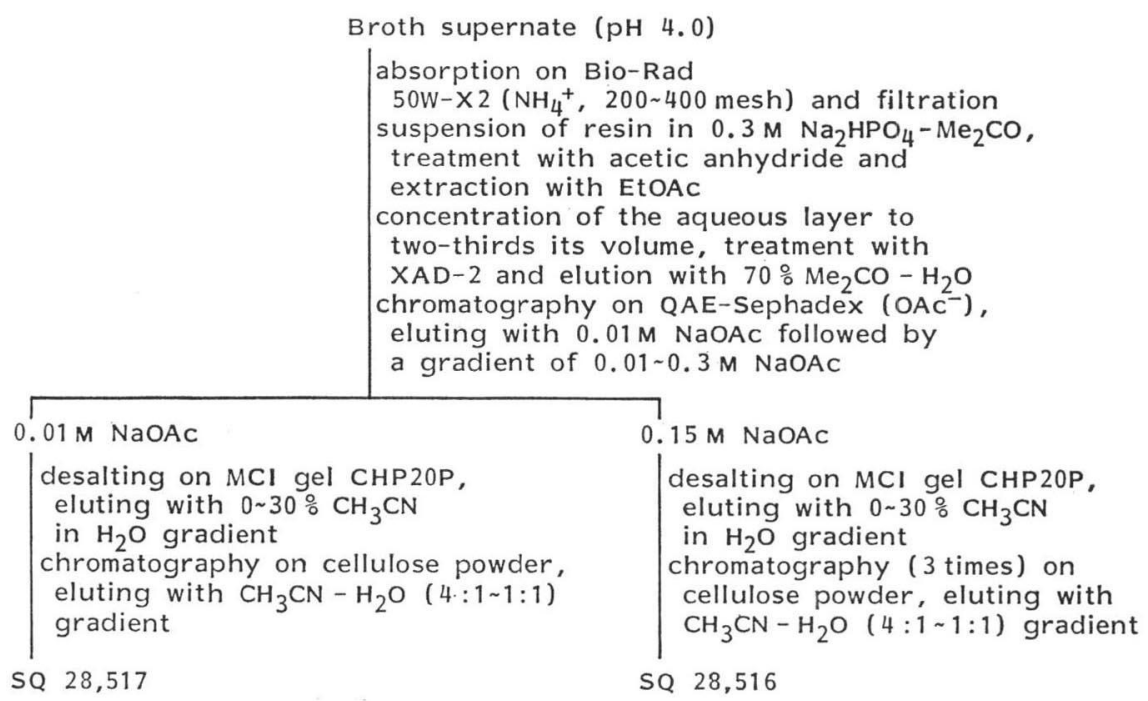

cephalosporin derivative.

Analysis of the acid hydrolysate $\left(6 \mathrm{~N} \mathrm{HCl}, 110^{\circ} \mathrm{C}, 15\right.$ hours) by dansylation ${ }^{12)}$ followed by TLC analysis on polyamide plates, indicated the presence of alanine, glycine, $\alpha$-aminoadipic acid and several unidentified components. The configurations of alanine and $\alpha$-aminoadipic acid, as the 2,3,4,6-tetra$O$-acetyl- $\beta$-D-glucopyranosyl isothiocyanate ${ }^{13)}$ (GITC) derivatives, were determined by HPLC using peak enhancement with authentic samples, and were shown to be $\mathrm{L}$ and $\mathrm{D}$, respectively. The presence of glycine ${ }^{142}$ and $\mathrm{D}$ - $\alpha$-aminoadipic acid in this hydrolysate was consistent with the formulation of SQ 28,516 as a cephalosporin derivative. 
Table 1. Electrophoresis of SQ 28,516, SQ 28,517 and the hydrolysis product (3).

\begin{tabular}{|c|c|c|c|}
\hline \multirow{2}{*}{ Buffer $(\mathrm{pH})$} & \multicolumn{3}{|c|}{ Mobility ${ }^{a}$} \\
\hline & SQ 28,516 & SQ 28,517 & 3 \\
\hline Sodium $0.05 \mathrm{M}$ phosphate $(2.3)$ & -0.17 & -0.43 & -0.48 \\
\hline Sodium $0.05 \mathrm{M}$ phosphate $(4.5)$ & +0.24 & -0.23 & -0.49 \\
\hline Sodium $0.05 \mathrm{M}$ phosphate $(7.0)$ & +0.25 & 0.00 & 0.00 \\
\hline Sodium 0.05 m carbonate $(9.2)$ & +0.24 & 0.00 & 0.00 \\
\hline
\end{tabular}

a On Whatman No. 1 paper, $12 \mathrm{~V} / \mathrm{cm}, 1$ hour; mobilities relative to vitamin $\mathrm{B}_{12}(0.00)$ and $p$-nitrobenzenesulfonate anion (1.00).

Table 2. ${ }^{1} \mathrm{H}$ NMR data for SQ 28,516, SQ 28,517 and the hydrolysis product (3).

\begin{tabular}{|c|c|c|c|c|}
\hline $\begin{array}{l}\text { Position } \\
\text { No. }\end{array}$ & $\begin{array}{l}\mathrm{SQ} 28,516 \\
\bar{\partial}(J \mathrm{~Hz})^{a}\end{array}$ & $\begin{array}{l}\text { SQ 28,517 } \\
\tilde{\partial}(J \mathrm{~Hz})^{a}\end{array}$ & $\begin{array}{l}\text { Position } \\
\text { No. }\end{array}$ & $\stackrel{3}{o\left(J^{\mathrm{Hz}}\right)^{a}}$ \\
\hline $34,38,42$ & $1.30(\mathrm{~m})$ & $1.30(\mathrm{~m})$ & $13,17,21$ & $1.25(\mathrm{~m})$ \\
\hline 26,27 & $1.40 \sim 1.80(\mathrm{~m})$ & $1.40 \sim 1.85(\mathrm{~m})$ & 5,6 & $1.40 \sim 1.52(\mathrm{~m})$ \\
\hline 12,13 & $1.60(\mathrm{~m})$ & $1.60(\mathrm{~m})$ & 24 & $1.70(\mathrm{~s})$ \\
\hline 18,45 & $1.95(\mathrm{~s})$ & $1.95(\mathrm{~s})$ & 2 & $\begin{array}{l}2.15(8.0,16.0) \\
2.31(4.0,16.0)\end{array}$ \\
\hline 11 & $2.30(\mathrm{~m})$ & $2.30(\mathrm{~m})$ & 7 & $3.08(\mathrm{~m})$ \\
\hline 23 & $\begin{array}{l}2.40(8.0,16.0) \\
2.60(4.0,16.0)\end{array}$ & $\begin{array}{l}2.40(8.0,16.0) \\
2.60(4.0,16.0)\end{array}$ & 4 & $3.70(\mathrm{~m})$ \\
\hline 28 & $3.10(\mathrm{~m})$ & $3.10(\mathrm{~m})$ & 3 & $3.85(\mathrm{~m})$ \\
\hline 2 & $\begin{array}{l}3.21(17.7) \\
3.55(17.7)\end{array}$ & $\begin{array}{l}3.21(17.7) \\
3.55(17.7)\end{array}$ & $12,16,20$ & $4.15(\mathrm{~m})$ \\
\hline 25 & $3.70(\mathrm{~m})$ & $3.70(\mathrm{~m})$ & & \\
\hline 24 & $3.90(\mathrm{~m})$ & $3.90(\mathrm{~m})$ & & \\
\hline 14 & $4.08(\mathrm{~m})$ & $4.10(\mathrm{~m})$ & & \\
\hline $33,37,41$ & $4.15(\mathrm{~m})$ & $4.15(\mathrm{~m})$ & & \\
\hline 20 & $\begin{array}{l}4.62(12.8) ; \\
4.78(12.8)\end{array}$ & $\begin{array}{l}4.70(12.8) ; \\
4.74(12.8)\end{array}$ & & \\
\hline 6 & $5.25(\mathrm{~s})$ & $5.25(\mathrm{~s})$ & & \\
\hline $7^{\prime}$ & $8.05(\mathrm{~s})$ & $8.00(\mathrm{~s})$ & & \\
\hline
\end{tabular}

a ppm downfield from TMS using HDO (4.73 ppm) as an internal standard.

The molecular weight and empirical formula of SQ 28,516 were determined by fast atom bombardment $(\mathrm{FAB})^{15)}$ mass spectrometry. Both positive and negative ion spectra implied molecular weights of 913 and 935 for the free acid and the monosodium salt, respectively. The exact mass observed for $\mathrm{C}_{36} \mathrm{H}_{50} \mathrm{~N}_{11} \mathrm{O}_{15} \mathrm{~S}(\mathrm{M}+\mathrm{H})$ was 914.362 (theory 914.367). Since SQ 28,516 was subsequently shown to be an $N, N^{\prime}$-diacetyl derivative, its parent antibiotic, which must have a molecular weight of 829 , would be the most complex cephalosporin isolated to date.

The ${ }^{1} \mathrm{H}$ NMR data for SQ 28,516 and assignments made with the aid of decoupling experiments are given in Table 2. The appearance of the peak assigned to the C-6 proton (singlet at $\delta$ 5.25) implied a 7,7-disubstituted moiety; however no methoxyl singlet was evident, eliminating cephamycins from consideration. The lack of a signal in the ${ }^{13} \mathrm{C}$ NMR spectrum $(\mathrm{ca} .96 \mathrm{ppm})^{16)}$ attributable to a 7-acylamino-7-oxygenated carbon, further indicated that SQ 28,516 was not a 7-alkoxy or acyloxy cephalosporin. The conjunction of peaks at $8.05 \mathrm{ppm}$ in the ${ }^{1} \mathrm{H}$ NMR spectrum and $77.8 \mathrm{ppm}$ in the ${ }^{13} \mathrm{C} \mathrm{NMR}$ spectrum strongly suggested a 7-acylamino-7-formamidocephalosporin. 
Table 3. ${ }^{13} \mathrm{C}$ NMR data for SQ 28,516.

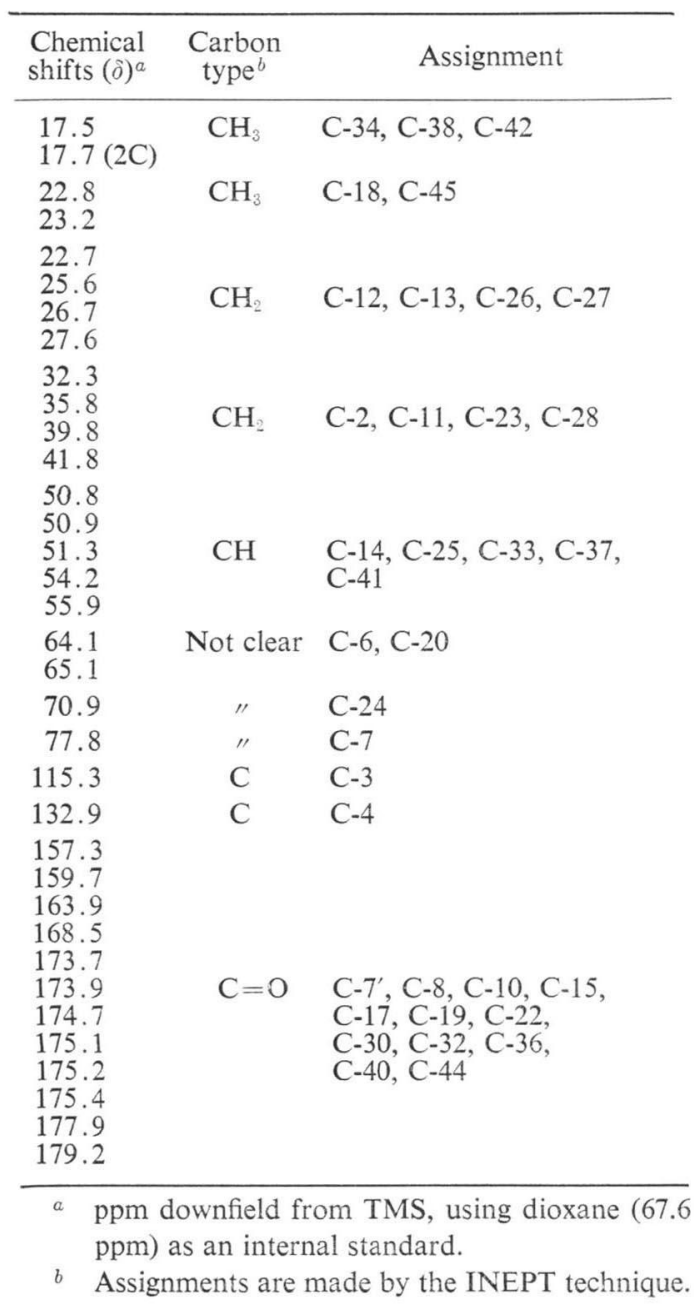

Fig. 3. Hydrolysis of SQ 28,516.
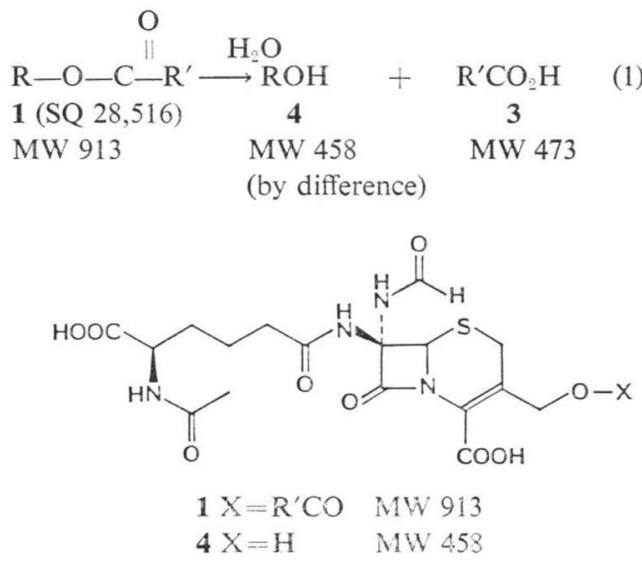

Though unreported as natural products, $7 \alpha$-formamidocephalosporins have recently been prepared synthetically ${ }^{17)}$. The chemical shifts reported for the $\mathrm{C}-6$ and $\mathrm{C}-\mathrm{7}^{\prime}$ protons were a striking match for those of SQ 28,516.

The ${ }^{13} \mathrm{C}$ NMR spectrum of $7 \alpha$-formamido$7 \beta$-phenylacylaminocephalosporanic acid (prepared using the procedure of MILnER ${ }^{17)}$ ) exhibited a peak at $\delta 79.1$ assigned to C-7. The correspondence in chemical shifts of the C-7 carbon of this material and SQ 28,516, together with the data discussed above, led us to assign a $7 \alpha$-formamido structure to SQ 28,516 and its parent antibiotic. The complete structural assignment of SQ 28,516 was based on the following consideration.

${ }^{1} \mathrm{H}$ NMR decoupling experiments indicated that the alanyl methyl protons $(\delta 1.30)$ were coupled to the alanyl methine protons $(\delta 4.15)$; the C-14 proton $(\delta 4.08)$ was coupled to the C-13 protons $(\delta 1.60)$; the C-11 protons ( $\delta 2.30)$ were coupled to the C-12 protons $(\delta 1.60)$; the C-25 proton $(\delta 3.70)$ was coupled to the C-24 proton $(\delta 3.90)$ and the protons at C-26 ( $\delta 1.40 \sim 1.80)$; and the C-28 protons $(\delta 3.10)$ were coupled to the $\mathrm{C}-27$ protons $(\delta 1.40 \sim 1.80)$.

The ${ }^{13} \mathrm{C}$ NMR data and assignments are presented in Table 3. The multiplicities of the carbons were determined using the INEPT ${ }^{18}$ ) technique.

Decomposition (via hydrolysis) of SQ 28,516 was facile and varying amounts of a hydrolysis product (3) were obtained during isolation and upon storage, even at $-20^{\circ} \mathrm{C}$. The hydrolysis product (3) is cationic at $\mathrm{pH} 2.3$ and 4.5 and uncharged at $\mathrm{pH} 7.0$ and 9.2 (Table 1), has an $\mathrm{Rf}$ of 0.15 on silica gel (Analtech $\mathrm{GH} 250, \mathrm{CH}_{3} \mathrm{CN}-\mathrm{H}_{2} \mathrm{O}, 7: 3$ ) and is positive in both the RYDON-SMITH and SAKAGUCHI tests but negative in the ninhydrin test. SQ 28,516, itself, has an Rf of 0.49 on silica gel (Analtech GH 250, $\mathrm{CH}_{3} \mathrm{CN}-\mathrm{H}_{2} \mathrm{O}, 7: 3$ ) and is positive in both the RYDON-SMITH and SAKAGUCHI tests but negative in the 
ninhydrin test.

The molecular weight and empirical formula of the hydrolysis product (3) were determined by FAB-MS ${ }^{15}$. Both positive and negative ion spectra indicated molecular weights of 473 and 495 for the free acid and the sodium salt, respectively. The exact mass observed for $\mathrm{C}_{18} \mathrm{H}_{88} \mathrm{~N}_{7} \mathrm{O}_{7}(\mathrm{M}+\mathrm{H})$ was 474.268 (theory 474.268). If our formulation of the origin of this hydrolysis product is correct, it should represent $\mathrm{R}^{\prime} \mathrm{CO}_{2} \mathrm{H}$ of equation 1 (Fig. 3). Correspondingly, the $\mathrm{ROH}$ portion should then be $N$-acetyl-7 $\alpha$-formamidodeacetylcephalosporanic acid (4). The correspondence of the molecular weight of 4 with that calculated strongly supports the formulation of SQ 28,516 as discussed herein.

The ${ }^{1} \mathrm{H}$ NMR data for the hydrolysis product (3) is presented in Table 2. Decoupling experiments indicated that the alanyl methyl protons $(\delta 1.25)$ were coupled to the alanyl methine protons $(\delta 4.15)$; the $\mathrm{C}-2$ protons $(\delta 2.15,2.31)$ were coupled to each other and to the proton at C-3 $(\delta 3.85)$; the C-3 proton $(\delta 3.85)$ was coupled to the C-2 protons $(\delta 2.15,2.31)$ and to the C-4 proton $(\delta 3.70)$; the C-4 proton $(\delta 3.70)$ was coupled to the C-5 protons $(\delta 1.40 \sim 1.52)$; and the protons at C-7 ( $\delta 3.08)$ were coupled to the protons at C-6 ( $\delta 1.40 \sim 1.52)$.

The sequence of amino acids in the hydrolysis product (3) was determined by FAB-MS. A mass analyzed ion kinetic energy (MIKE) spectrum ${ }^{18)}$ of the peak at $m / z 474(\mathrm{M}+\mathrm{H})^{+}$resulted in fragment ions at $m / z$ 386, 344, 273, 256, 202 and 185 establishing the sequence shown in Fig. 4.

Acid hydrolysis of compound 3 in $6 \mathrm{~N} \mathrm{HCl}$ at $110^{\circ} \mathrm{C}$ for 15 hours gave a mixture that was separated by ion-exchange chromatography into alanine and 3-hydroxy-4-amino-7-guanidoheptanoic acid. Alanine was assigned the L-configuration by peak enhancement on HPLC with authentic alanineGITC $^{13)}$ derivative. The identity of 3-hydroxy-4-amino-7-guanidoheptanoic acid was established by ${ }^{1} \mathrm{H}$ NMR and FAB-MS. A multiplet at $\delta 4.20$ (pH 1.0) was attributed to the methine proton at C-3 (unaffected by a change in $\mathrm{pH}$ ), a multiplet at $\delta 3.30(\mathrm{pH} 1.0)$ was attributed to the methine proton at C-4 (shifted to $\delta 2.65$ at pH 11.0), and a multiplet at $\delta 3.10(\mathrm{pH} 1.0 \sim 11.0)$ was attributed to the C-7 protons. Both positive and negative ion FAB-MS led to the conclusion that the molecular weight was 218 for the free acid.

SQ 28,517

A minor component of the fermentation, SQ 28,517 (2), a water soluble 7-substituted cephalosporin, was also isolated. In contrast to SQ 28,516 , SQ 28,517 is cationic at pH 2.3 and 4.5 and is uncharged

Fig. 4. Mass spectrometric fragmentation of the hydrolysis product (3).

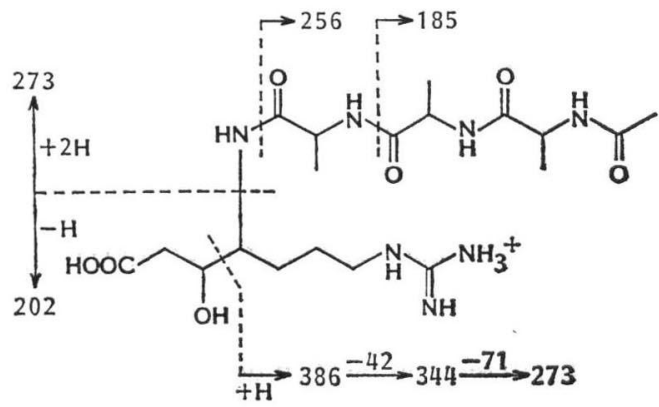

3
Table 4. Antibacterial activity of SQ 28,516.

\begin{tabular}{lrr}
\hline \multicolumn{1}{c}{ Organism } & SC No. & $\begin{array}{c}\text { MIC } \\
(\mu \mathrm{g} / \mathrm{ml})^{a}\end{array}$ \\
\hline Escherichia coli & 12155 & 100 \\
E. coli & 8294 & $>800$ \\
E. coli & 10857 & $>800$ \\
E. coli & 10896 & $>800$ \\
E. coli & 10909 & $>800$ \\
Proteus mirabilis & 3855 & $>800$ \\
P. rettgeri & 8479 & $>800$ \\
Staphylococcus aureus & 1276 & $>800$ \\
Streptococcus agalactiae & 9287 & 400 \\
Micrococcus luteus & 2495 & 25 \\
\hline
\end{tabular}

a Susceptibility determined by microtiter assay at $10^{3} \mathrm{cfu} / \mathrm{ml}$ in $\mathrm{AA}$ broth (BBL). 
at pH 7.0 and 9.2 (Table 1). SQ 28,517 has an $\mathrm{Rf}$ of 0.3 on silica gel (Analtech $\mathrm{GH} 250, \mathrm{CH}_{3} \mathrm{CN}-\mathrm{H}_{2} \mathrm{O}$, 7:3) and is positive in the RYDon-SMItH and SAKaGUCHI tests and negative in the ninhydrin test. Analysis of the acid hydrolysate $\left(6 \mathrm{~N} \mathrm{HCl}, 110^{\circ} \mathrm{C}, 15\right.$ hours) by dansylation ${ }^{13)}$ followed by TLC analysis on polyamide plates indicated the presence of alanine, glycine, $\alpha$-aminoadipic acid and several unidentified products.

The positive-ion FAB-MS of SQ 28,517 did not give a parent ion. The UV spectrum showed a $\lambda_{\max }$ at $265 \mathrm{~nm}\left(\mathrm{E}_{\mathrm{com}}^{1 \% \%} 33\right)$ and the IR spectrum in $\mathrm{KBr}$ exhibited bands at 1760 ( $\beta$-lactam carbonyl), 1720 (ester) and 1650 (secondary amide) $\mathrm{cm}^{-1}$.

The ${ }^{1} \mathrm{H}$ NMR data for SQ 28,517 is given in Table 2, and is similar to the data for SQ 28,516. The chemical shift of the $\beta$-lactam proton at C-6 $(\delta 5.25)$ and the C-7' proton $(\delta 8.00)$ are analogous to those observed for SQ 28,516.

The C-20 side chain of SQ 28,517 was shown to be the same as that in SQ 28,516, by the analysis described above. Structure $\mathbf{2}$ is consistent with the spectroscopic and electrophoretic data presented in this paper, and is thus a reasonable candidate for SQ 28,517.

\section{Conclusion}

In conclusion, two novel 7 -formamidocephalosporins have been isolated as their $N, N^{\prime}$-diacetyl derivatives (SQ 28,516 and SQ 28,517) from a bacterial culture. SQ 28,516 exhibits weak antibacterial activity (Table 4). To the best of our knowledge, these constitute the most complex naturally-produced cephalosporins isolated to date. The same bacterial culture produces deacetoxycephalosporin $\mathrm{C}^{11}$. The origin of the nitrogen at C-7 in SQ 28,516 and SQ 28,517 poses an interesting biosynthetic problem. Also, whether deacetoxycephalosporin $\mathrm{C}$ and the 7-formamidocephalosporins are biosynthetically related is unknown. With the discovery of monobactams ${ }^{1 \sim 8)}$, a carbapenem ${ }^{10)}$, and cephalosporins ${ }^{11)}$ of bacterial origin, it is obvious that bacteria have the biosynthetic capability to produce a range of $\beta$ lactam-containing structures at least comparable to those produced by streptomycetes and fungi.

\section{Experimental}

NMR spectra were determined on a Joel Ltd. GX 400 spectrometer. IR spectra were recorded on a Perkin-Elmer model 621 spectrometer. Rotations were measured on a Perkin-Elmer model 141 polarimeter. Mass spectra were determined on a VG Analytical Ltd. model ZAB 1F spectrometer.

Isolation of SQ 28,516 and SQ 28,517

At harvest, the cells from a 20-liter fermentation of Flavobacterium sp. SC 12,154 were separated by centrifugation. The $\mathrm{pH}$ of the broth supernate (20 liters) was adjusted to 4.0 with $\mathrm{HCl}$ and the bioactive components were absorbed onto ion-exchange resin Bio-Rad 50W-X2 $\left(\mathrm{NH}_{4}{ }^{+}, 200 \sim 400\right.$ mesh, $350 \mathrm{~g}$, batch process, 2 hours). The resin was filtered, washed with $\mathrm{H}_{2} \mathrm{O}$ (1 liter) and suspended in a mixture of $0.3 \mathrm{M} \mathrm{Na}_{2} \mathrm{HPO}_{4}(\mathrm{pH} 8.2,2.5$ liters$)$ and acetone $(250 \mathrm{ml})$. Aliquots of acetic anhydride $(7.5 \mathrm{ml})$ were added to the suspension with stirring (four times at 40 -minute intervals) and the $\mathrm{pH}$ of the reaction mixture was maintained at about 8 with $3 \mathrm{~N} \mathrm{NaOH}$. After 2 hours of stirring, the resin was removed by filtration and washed with $\mathrm{H}_{2} \mathrm{O}(500 \mathrm{ml})$. The aqueous solution was extracted with EtOAc $(2 \times 2$ liters $)$. The EtOAc layer was discarded and the aqueous layer was concentrated to two-thirds its volume and stirred with Amberlite XAD-2 resin ( $500 \mathrm{ml}, 2$ hours). The resin was filtered, washed with $\mathrm{H}_{2} \mathrm{O}$ (1 liter) and packed in a column. The bioactive components were eluted with $70 \%\left(\mathrm{CH}_{3}\right)_{2} \mathrm{CO}-\mathrm{H}_{2} \mathrm{O}$ (3 liters). The bioactive fractions were combined and the solvents were removed under reduced pressure (temperature $\left.<35^{\circ} \mathrm{C}\right)$. The residue $(1.28 \mathrm{~g})$ was dissolved in $\mathrm{H}_{2} \mathrm{O}(10 \mathrm{ml})$ and purified on an ion-exchange column of Sephadex QAE (OAc ${ }^{-}, 200 \sim 400$ mesh, $2.5 \times 17 \mathrm{~cm}$ ) that had been equilibrated with $0.01 \mathrm{~m}$ $\mathrm{NaOAc}$. The column was eluted with $0.01 \mathrm{M} \mathrm{NaOAc}(500 \mathrm{ml})$ followed by a gradient of $0.01 \sim 0.3 \mathrm{M}$ $\mathrm{NaOAc}$ (1.5 liters). SQ 28,517 was not retained on the resin and eluted with $0.01 \mathrm{~m} \mathrm{NaOAc}$ whereas 
SQ 28,516 was retained on the resin and eluted at $0.15 \mathrm{M} \mathrm{NaOAc}$.

The bioactive fractions containing SQ 28,517 $(200 \mathrm{ml})$ were desalted on a column of MCI gel CHP$20 \mathrm{P}(2.5 \times 20 \mathrm{~cm})$. The column was washed with $\mathrm{H}_{2} \mathrm{O}(400 \mathrm{ml})$ and the activity was eluted with a gradient of $0 \sim 30 \% \mathrm{CH}_{3} \mathrm{CN}-\mathrm{H}_{2} \mathrm{O}(800 \mathrm{ml})$. The bioactive fractions were combined and concentrated. The residue $(108 \mathrm{mg})$ was further purified on a column of cellulose $(2.5 \times 20 \mathrm{~cm})$ eluting with a gradient of 4: $1 \sim 1: 1, \mathrm{CH}_{3} \mathrm{CN}-\mathrm{H}_{2} \mathrm{O}(800 \mathrm{ml})$. The bioactive fractions were combined and concentrated to give chromatographically homogeneous SQ $28,517(6.3 \mathrm{mg})$ as an off-white foam.

The bioactive fractions containing SQ 28,516 $(250 \mathrm{ml})$, from the Sephadex QAE column, were desalted on a column of MCI gel CHP20P $(2.5 \times 25 \mathrm{~cm})$. The column was washed with $\mathrm{H}_{2} \mathrm{O}(450 \mathrm{ml})$ and then eluted with a gradient of $0 \sim 30 \% \mathrm{CH}_{3} \mathrm{CN}-\mathrm{H}_{2} \mathrm{O}(800 \mathrm{ml})$. The bioactive fractions were combined and concentrated to dryness. The residue $(116 \mathrm{mg})$ was further purified on a cellulose column $(2.5 \times 24.5 \mathrm{~cm})$ eluting with a gradient of $4: 1 \sim 1: 1, \mathrm{CH}_{3} \mathrm{CN}-\mathrm{H}_{2} \mathrm{O}(1.2$ liters $)$. The bioactive fractions were combined and concentrated to dryness $(20.2 \mathrm{mg})$. The cellulose chromatography was repeated twice on the $20.2 \mathrm{mg}$ sample using the same gradient, to give chromatographically homogeneous SQ $28,516(16.2 \mathrm{mg})$ as an off-white foam.

Isolation of Hydrolysis Product (3)

After storage for four months at $-20^{\circ} \mathrm{C}$, TLC of a sample of SQ 28,516 showed the presence of hydrolysis product (3). This sample $(39.6 \mathrm{mg})$ was chromatographed on a cellulose column $(2.5 \times 25$ $\mathrm{cm}$ ), eluting with a gradient of $4: 1 \sim 1: 1, \mathrm{CH}_{3} \mathrm{CN}-\mathrm{H}_{2} \mathrm{O}$ (1.2 liters), to yield $24.2 \mathrm{mg}$ of SQ 28,516 and $11.5 \mathrm{mg}$ of hydrolysis product (3).

Hydrolysis of 3

A solution of $7.75 \mathrm{mg}$ of the hydrolysis product (3) in $1.5 \mathrm{ml}$ of $6 \mathrm{~N} \mathrm{HCl}$ was heated at $110^{\circ} \mathrm{C}$ for 15 hours and then concentrated in vacuo. The residue was chromatographed on a $1.1 \times 16 \mathrm{~cm}$ column of Dowex 50W-X2 resin (200 400 mesh, pyridinium form) eluting with a linear gradient of $0.2 \sim 2.0 \mathrm{M}$ pyridinium acetate ( $\mathrm{pH} 5.1$ ), to give alanine $(4.7 \mathrm{mg})$ and 3-hydroxy-4-amino-7-guanidoheptanoic acid $(2.8 \mathrm{mg}) .{ }^{1} \mathrm{H}$ NMR of 3-hydroxy-4-amino-7-guanidoheptanoic acid $\left(\mathrm{D}_{2} \mathrm{O}, \mathrm{pH} 7\right): \delta 1.50 \sim 1.70(\mathrm{~m})$, $2.35(\mathrm{t}), 3.15(\mathrm{~m})$ and $4.15(\mathrm{~m})$.

\section{Acknowledgments}

The authors wish to thank Mr. P. A. PrinciPe and Mr. R. HugiLl for providing fermentation broths, Dr. S. K. TANAKa for obtaining MIC values, Drs. S. Unger and P. T. Funke for obtaining MS data and Dr. M. PorubCan and Ms. A. Kahle for NMR data. Helpful discussions with Dr. W. L. PARKer are gratefully acknowledged.

\section{References}

1) Imada, A.; K. Kitano, K. Kintaka, M. Muror \& M. Asai: Sulfazecin and isosulfazecin, novel $\beta$-lactam antibiotics of bacterial origin. Nature 289: 590 591, 1981

2) Asai, M.; K. Haibara, M. Muroi, K. Kintaka \& T. Kishi: Sulfazecin, a novel $\beta$-lactam antibiotic of bacterial origin. Isolation and chemical characterization. J. Antibiotics 34: 621 627, 1981

3) Sykes, R. B.; C. M. Cimarusti, D. P. Bonner, K. Bush, D. M. Floyd, N. H. Georgopapadakou, W. H. Koster, W. C.' Liu, W. L. Parker, P. A. Principe, M. L. Rathnum, W. A. Slusarchyk, W. H. Trejo \& J. S. Wells: Monocyclic $\beta$-lactam antibiotics produced by bacteria. Nature 291: 489 491, 1981

4) Wells, J. S.; W. H. Trejo, P. A. Principe, K. Bush, N. Georgopapadakou, D. P. Bonner \& R. B. Sykes: SQ 26,180, a novel monobactam. I. Taxonomy, fermentation and biological properties. J. Antibiotics 35: $184 \sim 188,1982$

5) Parker, W. L.; W. H. Koster, C. M. Cimarusti, D. M. Floyd, W. C. Liu \& M. L. Rathnum: SQ 26,180, a novel monobactam. II. Isolation, structure determination and synthesis. J. Antibiotics 35: 189 195, 1982

6) Wells, J. S.; W. H. Trejo, P. A. Principe, K. Bush, N. Georgopapadakou, D. P. Bonner \& R. B. Sykes: EM5400, a family of monobactam antibiotics produced by Agrobacterium radiobacter. I. Taxonomy, fermentation and biological properties. J. Antibiotics 35: 295 299, 1982 
7) Parker, W. L. \& M. L. Rathnum: EM5400, a family of monobactam antibiotics produced by Agrobacterium radiobacter. II. Isolation and structure determination. J. Antibiotics 35: 300 305, 1982

8) Cooper, R.; K. Bush, P. A. Principe, W. H. Trejo, J. S. Wells \& R. B. Sykes: Two new monobactam antibiotics produced by a Flexibacter sp. I. Taxonomy, fermentation, isolation and biological properties. J. Antibiotics 36: 1252 1257, 1983

9) Singh, P. D.; J. H. Johnson, P. C. Ward, J. S. Wells, W. H. Trejo \& R. B. Sykes: SQ 28,332, a new monobactam produced by a Flexibacter sp. Taxonomy, fermentation, isolation, structure determination and biological properties. J. Antibiotics 36: 1245 1251, 1983

10) Parker, W. L.; M. L. Rathnum, J. S. Wells, W. H. Trejo, P. A. Principe \& R. B. Sykes: SQ 27,860 a simple carbapenem produced by species of Serratia and Erwinia. J. Antibiotics 35: 653 660, 1982

11) Singh, P. D.; P. C. Ward, J. S. Wells, C. M. Ricca, W. H. Trejo, P. A. Principe \& R. B. Sykes: Bacterial production of deacetoxycephalosporin C. J. Antibiotics 35: 1397 1399, 1982

12) Weiner, A. M.; T. Platt \& K. Weber: Amino-terminal sequence analysis of proteins purified on a nanomole scale by gel electrophoresis. J. Biol. Chem. 247: $3242 \sim 3251,1972$

13) Kinoshita, T.; Y. KASAHARA \& N. NimURA: Reversed phase high-performance liquid chromatographic resolution of non-esterified enantiomeric amino acids by derivatization with 2,3,4,6-tetra- $O$-acetyl- $\beta$-Dglucopyranosyl isothiocyanate and 2,3,4-tri- $O$-acetyl- $\alpha$-D-arabinopyranosyl isothiocyanate. J. Chromatogr. 210: $77 \sim 81,1981$

14) Brannon, D. R.; J. A. Mabe, R. Ellis, J. G. Whitney \& R. Nagarajan: Origin of glycine from acid hydrolysis of the $\beta$-lactam antibiotic A16886B. Antimicrob. Agents Chemother. 1: 242 246, 1972

15) Barber, M.; R. S. Bordoli, R. D. SedGwick \& A. N. Tyler: Fast atom bombardment of solids (F.A.B.): A new ion source for mass spectrometry. J. Chem. Soc., Chem. Commun. 1981: 325 327, 1981

16) Paschal, J. W.; D. E. Dorman, P. R. Srinivasan \& R. L. Lichter： Nuclear magnetic resonance spectroscopy. Carbon-13 and nitrogen-15 spectra of the penicillins and cephalosporins. J. Org. Chem. 43: 2013 2016, 1978

17) Milner, P. H.: Alpha-formamide-substituted beta-lactam compounds - useful as broad spectrum antibacterials and intermediates. Eur. Pat. Appl. 71,395, Feb. 9, 1983

18) Doddrel, D. M. \& D. T. PEGG: Assignment of proton-coupled carbon-13 spectra of complex molecules by using polarization transfer spectroscopy. A superior method to off-resonance decoupling. J. Am. Chem. Soc. 102: 6388 6390, 1980

19) Cooks, R. G.; J. H. Beynon, R. M. Capriolic \& G. R. Lester: Metastable Ions. Elesevier, New York, 1973 